\title{
Best practices for modeling structural boundary conditions due to a localized fire
}

\author{
Alyssa DeSimone (iD I Ann E. Jeffers
}

Department of Civil and Environmental Engineering, University of Michigan, Ann Arbor, Michigan

\section{Correspondence}

Alyssa DeSimone, Department of Civil and Environmental Engineering, University of Michigan, Ann Arbor, Ml.

Email: adesimon@umich.edu

Funding information

Regents Fellowship; Gerstacker Fellowship

\begin{abstract}
Summary
Recent studies suggest the assumption of uniform heating that is used in current structural fire design cannot be assumed conservative, especially if the fire is expected to burn locally. Aside from design equations, which have limited applicability, a common approach to simulating structural members subjected to a localized fire is modeling the fire-structure interaction using a coupled computational fluid dynamics (CFD)-finite element (FE) model. In the existing literature, a wide range of methods and parameters are used when determining the boundary conditions at the firestructure interface, specifically regarding the representation of net heat flux, heat transfer coefficient, and surface emissivity of steel. The purpose of this study is to investigate various methods for representing the boundary conditions in terms of accuracy and computational efficiency and then identify best practices. In conclusion, our study found that net heat flux predicted by adiabatic surface temperature, a nonconstant heat transfer coefficient, and a surface emissivity of 0.9 for steel was the most reliable thermal boundary condition in a coupled CFD-FE model of a localized fire. These recommendations are based on the two cases studied here, and caution should be used when applying these results to future studies.
\end{abstract}

\section{KEYWORDS}

CFD-FE coupling, fire-structure interaction, localized fire, non-uniform heating

\section{1 | INTRODUCTION}

Recent studies suggest that the assumption of uniform heating used in current structural fire design cannot be assumed to be conservative, especially in the case of localized fires. Zhang et al $^{1}$ suggests that the failure mode of a beam may be different if it is exposed to a localized fire instead of the standard fire curve. In particular, Zhang et al $^{1}$ found that when many beams were subjected to the standard fire curve, they failed due to deflection limitations, but when they were subjected to a localized fire, they failed due to buckling. A study by Dwaikat et $\mathrm{al}^{2}$ on the effect of thermal gradients in steel columns concluded that the thermal gradient caused a bending moment in the column, which reduced the column's capacity. These studies suggest that structural members subjected to thermal gradients behave fundamentally different from how they were originally conceived, leading to the potential of a premature failure. In addition, another study by Zhang et $\mathrm{al}^{3}$ found that the failure temperature of steel columns subjected to an adjacent localized fire could be higher or lower than the failure temperature predicted by the standard fire curve. These studies show that the current design codes do not have the capability to predict the behavior of structural elements subjected to localized heating, and therefore, a more detailed approach to modeling these structures is needed.

\section{2 | BACKGROUND}

A common approach to simulating structural members subjected to a localized fire is a coupled computational fluid dynamics (CFD)-finite element (FE) model. The CFD analysis of the fire allows for the full consideration of the nonuniform effect of the localized fire. Heat flux 
and temperature data from the CFD analysis are passed to the FE model as a thermal boundary condition, and the FE analysis determines the thermal and mechanical response of the structure. An example of this can be seen in Figure 1, where the image on the left is the CFD simulation of an I-beam subjected to a pool fire. Data from the CFD simulation is transferred to the FE analysis, and the image on the right shows the solid heat transfer analysis of the I-beam due to the pool fire.

The study described in this paper focuses on the representation of the boundary condition at the structure-fire interface for coupled CFD-FE analyses of localized fires. In the existing literature, ${ }^{4-9}$ many different methods and parameters have been used when determining the thermal boundary conditions at the fire-structure interface. The issue is that the methods being used lack consistency, which could lead to significant modeling errors when applied in practice. The purpose of this study is to investigate the existing methods for accuracy and computational efficiency and then to identify best practices so as to guide readers in the very complicated CFD-FE analysis of structures in fire. This study also aims to show the impact that certain modeling assumptions can have on the prediction of structural response. The main inconsistencies found in the literature were related to the representation of solid temperatures, the convective heat transfer coefficient, and the surface emissivity of steel at the structure-fire interface.

Net heat flux is used as the thermal boundary condition, and two different representations of net heat flux are considered in this study, which employ different models for heat transfer in the solid. Heat flux is defined as a flow of energy per unit area per unit time. The net heat flux to a surface can be predicted by the incident radiative heat flux and the gas temperature, the adiabatic surface temperature ${ }^{4}$ (AST), or directly in the CFD simulation. The first two methods listed use the FE conduction model to determine solid temperature while the final method listed uses the CFD code's solid conduction model. Next, the convective heat transfer coefficient was considered, which is a parameter used to determine the convective heat flux component of the boundary condition. This study considers the heat transfer coefficient as a constant value of $35 \mathrm{~W} / \mathrm{m}^{2} \mathrm{~K}$ (as specified in Eurocode ${ }^{5}$ and Tondini et $\mathrm{al}^{6}$ ) or $9 \mathrm{~W} / \mathrm{m}^{2} \mathrm{~K}$ (as specified in Zhang et $\mathrm{al}^{7}$ ) or calculated directly from the CFD analysis (as recommended in Silva et $\mathrm{al}^{8}$ ). In addition, the surface emissivity of steel is explored in this study. Emissivity is the ratio between the radiative heat absorbed by the surface to that absorbed by a blackbody, and it is related to determining the radiative heat flux to a solid. Eurocode ${ }^{5}$ suggests using a value of 0.7

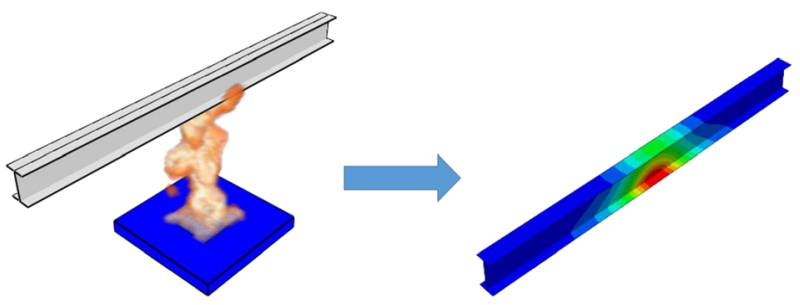

FIGURE 1 CFD-FE coupling schematic [Colour figure can be viewed at wileyonlinelibrary.com] for calculations of steel exposed to fire, and the value of 0.9 has been used for the emissivity of steel when considering localized fires. ${ }^{9}$ Furthermore, The ASCE Manuals and Reports on Engineering Practice No. 138, Structural Fire Engineering ${ }^{10}$ reports the emissivity of steel at room temperature to be between 0.2 and 0.9 and recommends a value towards the higher end of the provided range when modeling unprotected steel under fire exposure as a conservative measure because soot may adhere to the surface of the steel.

This study considers the various methods and parameters described above in two localized fire scenarios. The first scenario considers a square hollow section (SHS) column subjected to an adjacent burner fire, which has been tested experimentally. ${ }^{11}$ The second scenario consists of a steel I-beam subjected to a pool fire at mid-span, which was experimentally tested at the University of Edinburgh. ${ }^{12}$

\section{3 | VALIDATION STUDIES}

\section{1 | Case 1-experiment by Kamikawa et al}

Case 1 is modeled after an experiment conducted by Kamikawa et al. ${ }^{11}$ It consisted of an SHS column subjected to an adjacent burner fire. Specifically, the fire source was a square diffusion burner (dimensions: $0.3 \mathrm{~m} \times 0.3 \mathrm{~m} \times 0.25 \mathrm{~m}$ tall) located beside the base of the column. The fuel source was propane, and the heat release rate (HRR) was kept constant at $52.5 \mathrm{~kW}$. The column section tested was STKR400, with dimensions, $0.1 \mathrm{~m} \times 0.1 \mathrm{~m} \times 1.6 \mathrm{~m}$ and a 3.2-mm wall thickness. The column was only restrained at the base where a fixed boundary condition was imposed. The experiment conducted by Kamikawa et $\mathrm{al}^{11}$ included four different test cases; the case studied here is referred to as case 1 in their work. This experiment was conducted to study the thermal and mechanical response of the column as a result of thermal expansion and no mechanical load placed on the column. Figure 2 displays the experimental setup. ${ }^{11}$ The setup depicts the column within a load bearing frame and an oil jack set above the specimen. The oil jack was controlled by an electric hydraulic pump. Installed between the specimen and the jack were a load cell for axial force (although no axial force was applied in the case studied here), a cylindrical sliding bearing, and a cruciform steel plate for

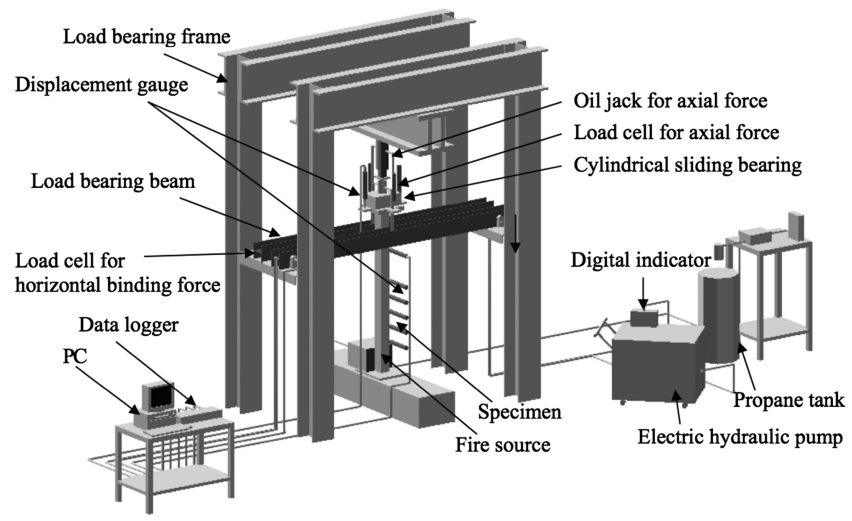

FIGURE 2 Experimental setup in Kamikawa et al ${ }^{10}$ 
vertical displacement measurements. Partition walls for smoke exhaust were placed around the experimental apparatus. ${ }^{11}$

\section{2 | Case 2-experiment by University of Edinburgh}

Case 2 is modeled after an experiment performed at the University of Edinburgh. ${ }^{12}$ It consisted of a steel I-beam subjected to a pool fire at mid-span. The fire source was a 0.4-m square heptane pool fire with a mass of $1.6 \mathrm{~kg}$. The fire was located $1 \mathrm{~m}$ below the beam at midspan. The I-beam used in the test was a simply supported $203 \times 133$ $\times 30$ UB section. The measured mass loss rate of the heptane fuel was $0.0203 \mathrm{~kg} / \mathrm{m}^{2} \mathrm{~s}$. This experiment was conducted as part of a round-robin study to examine the consistency of different modeling approaches to determine the thermal response of a beam subjected to a pool fire. There was no mechanical load placed on the beam in this study. The test setup ${ }^{12}$ is shown in Figure 3 . The setup depicts the beam being simply supported by two metal stands. The fire is located under the beam at mid-span, and the fire source was placed in a water bath.

\section{4 | METHODOLOGY AND NUMERICAL MODELS}

This study uses a one-way (or weak) coupling algorithm to couple the CFD-FE analyses, illustrated in Figure 4. In a one-way coupling scheme, the CFD and FE analyses are run separately, and information from the CFD simulation, namely, temperature and heat flux data, is transferred to the FE model, which determines the thermal and mechanical response of the structure. There is no feedback from the FE analysis to the CFD code. Broadly, this means that characteristics

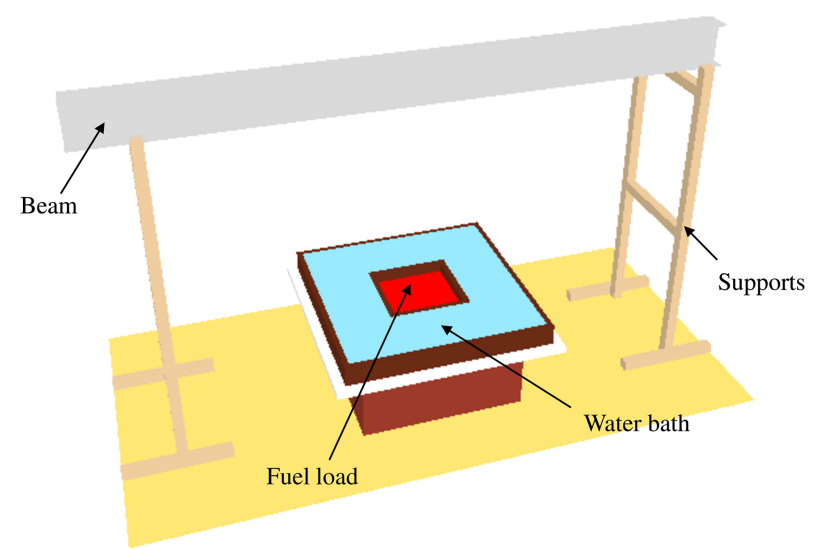

FIGURE 3 Experimental setup in Higginson et al ${ }^{11}$ [Colour figure can be viewed at wileyonlinelibrary.com] captured in the FE analysis such as displacements and other changes in geometry are not considered in the CFD simulation. Spatial ${ }^{13}$ and temporal ${ }^{14}$ homogenization algorithms were used to overcome differences in the space and time scale used in the CFD and FE analyses.

The CFD code used to model the localized fire in this study was fire dynamics simulator (FDS) developed by NIST. Specifically, version 6.6.0 was used for the analyses presented in this report. FDS numerically solves a form of the Navier-Stokes equation that can be used for "low-speed, thermally-driven flow." Turbulence is modeled using large eddy simulation (LES). The combustion model uses a single step, mixing-controlled chemical reaction that uses three lumped species (ie, air, fuel, and products), and radiative heat transfer is solved for using the radiation transport equation for gray gas. ${ }^{15}$

Temperature-dependent material properties were used for the steel members in both the CFD and FE models. The temperaturedependent Eurocode ${ }^{5}$ models for conductivity and specific heat were input into both the CFD and FE models, and the stress-strain model and thermal expansion model from Eurocode ${ }^{5}$ were used in the $\mathrm{FE}$ analysis. The elastic modulus used was $202000 \mathrm{MPa}$, and the yield strength used was $404 \mathrm{MPa}$.

The spatial mesh for the CFD code was determined based on the equation for the characteristic diameter of a plume ${ }^{15}$ :

$$
\mathrm{D}^{*}=\left(\frac{\dot{\mathrm{Q}}}{\mathrm{p}_{\infty} \mathrm{c}_{\mathrm{p}} \mathrm{T}_{\infty} \sqrt{\mathrm{g}}}\right)^{\frac{2}{5}}
$$

where $D^{*}$ is the characteristic diameter of the plume $(\mathrm{m}), \dot{Q}$ is the total heat release rate $(\mathrm{kW}), p_{\infty}$ is the ambient air density $\left(\mathrm{kg} / \mathrm{m}^{3}\right), c_{p}$ is the ambient specific heat of air $(\mathrm{kJ} / \mathrm{kg}-\mathrm{K}), T_{\infty}$ is the ambient air temperature $(K)$, and $g$ is the acceleration of gravity $\left(\mathrm{m} / \mathrm{s}^{2}\right)$.

The characteristic diameter of the plume can then be used to determine mesh size using the

following relation:

$$
\mathrm{R}^{*}=\frac{\mathrm{dx}}{\mathrm{D}^{*}}
$$

where $R^{*}$ is the spatial resolution and $d x$ mesh size $(\mathrm{m})$.

Using Equations (1) and (2), a mesh size of $0.025 \mathrm{~m}$ was found to be sufficient for both cases 1 and 2 (assuming $R^{*}=1 / 12$ ) as recommended. ${ }^{9}$ Additionally, a CFD mesh sensitivity study was carried out for case 1. Because of the similar nature of cases 1 and 2 and that the same mesh size was used, an additional mesh sensitivity analysis was not carried out for case 2 . The results of the CFD mesh sensitivity study are presented in Figure 5. A mesh size of $d x=0.025 \mathrm{~m}$ and $d x=$ $0.0125 \mathrm{~m}$ were tested and compared. Figure 5A presents the thermal results recorded on the center of the front side of the column (closest to the fire) measured $400 \mathrm{~mm}$ from the base. Figure 5B presents the
FIGURE 4 One-way weak coupling algorithm [Colour figure can be viewed at wileyonlinelibrary.com]

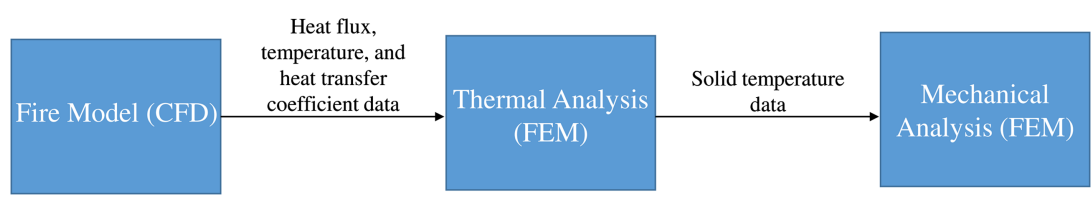



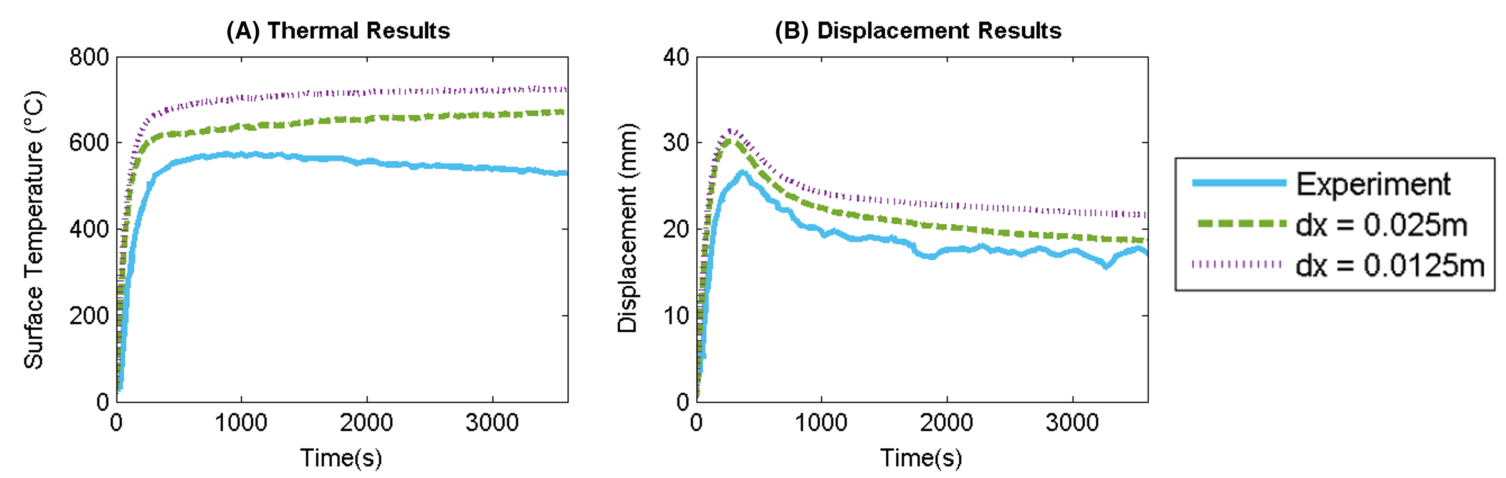

FIGURE 5 Computational fluid dynamics mesh study: A, thermal results and B, displacement results [Colour figure can be viewed at wileyonlinelibrary.com]

displacement results recorded on the center of the front side of the column (closest to the fire) measured $1440 \mathrm{~mm}$ from the base. The refined CFD mesh $(d x=0.0125 \mathrm{~m}$ ) predicted higher temperatures as seen in Figure 5A and larger displacements as seen in Figure 5B. In Figure $5 \mathrm{~A}$, the maximum difference in predicted temperature between the original mesh $(d x=0.025 \mathrm{~m})$ and the refined mesh $(d x=0.0125$ $\mathrm{m}$ ) is less than $10 \%$. In Figure 5B, the maximum difference in predicted displacement between the original mesh $(d x=0.025 \mathrm{~m})$ and the refined mesh $(d x=0.0125 \mathrm{~m})$ is approximately $14 \%$. These results confirm that refining the CFD mesh does not notably impact the results and does not justify the significant increase in computational expense that would be required.

The CFD computational domain used in case 1 was $0.75 \mathrm{~m} \times 0.45 \mathrm{~m}$ $\times 1.8 \mathrm{~m}$, and the computational domain used in case 2 was $3.0 \mathrm{~m} \times 1.5 \mathrm{~m}$ $\times 2.0 \mathrm{~m}$. The edges of the computational domain were modeled as "open vents" in FDS, meaning a passive opening to the outside where ambient conditions exist. ${ }^{15}$ It is important to the validity of CFD simulations that the open vents are modeled far enough away from the regions of interest as to not disrupt flow patterns. To validate the choice of the domain size used in this study, additional CFD analyses were run for cases 1 and 2 where the computational domain was extended by $0.5 \mathrm{~m}$ in five directions $(+x,-x,+y,-y$, and $+z)$ and compared with the original smaller domain size. The domain size of the extended boundary for case 1 was $1.75 \mathrm{~m} \times 1.45 \mathrm{~m} \times 2.3 \mathrm{~m}$, and the extended domain size for case 2 was $4.0 \mathrm{~m} \times 2.5 \mathrm{~m} \times 2.5 \mathrm{~m}$. The results of the analysis of domain size are presented in Figure 6. Figure 6A presents the thermal results for case 1 recorded at the center of the front face of the column (closest to the fire) and $400 \mathrm{~mm}$ from the base. Figure 6B presents the thermal results for case 2, recorded at mid-span and mid-web of the beam. The figures show that increasing the computational domain does not significantly impact the results of this study.

In this study, the relevant CFD data were output at every computational volume in the CFD code that contained a structural surface. This was done to completely capture the nonuniformity of the localized fire and create the fullest representation of the CFD fire model one could achieve in FE model. Smokeview images from the CFD analyses are shown for case 1 (Figure 7A) and case 2 (Figure 7B).

Finite element models were created for both cases using Abaqus. For case 1, a coupled temperature-displacement analysis was performed using the S4T element type. The S4T coupled temperaturedisplacement element is a four-node general-purpose shell element with finite membrane strains and bilinear temperature in the shell surface. This element was chosen for this analysis because it can be used in a coupled temperature-displacement model and the thin walls of the column could be properly modeled with a shell element. A mesh size of $0.01 \mathrm{~m}$ was used along the height and width of the column. For case 2 , a heat transfer analysis was performed using the DS4 element type. The DS4 heat transfer element is a four-node quadrilateral shell element. This element was chosen for this analysis because it can be used in a heat transfer model, and the thin web and flange of the beam could be properly modeled with a shell element. A mesh size of 0.01 $\mathrm{m}$ was used along the height and length of the beam.
(A) Case 1

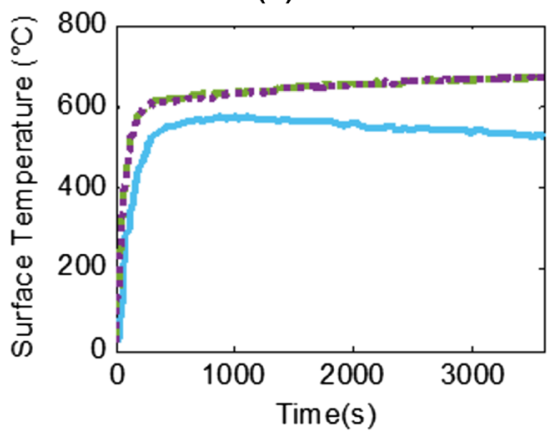

(B) Case 2

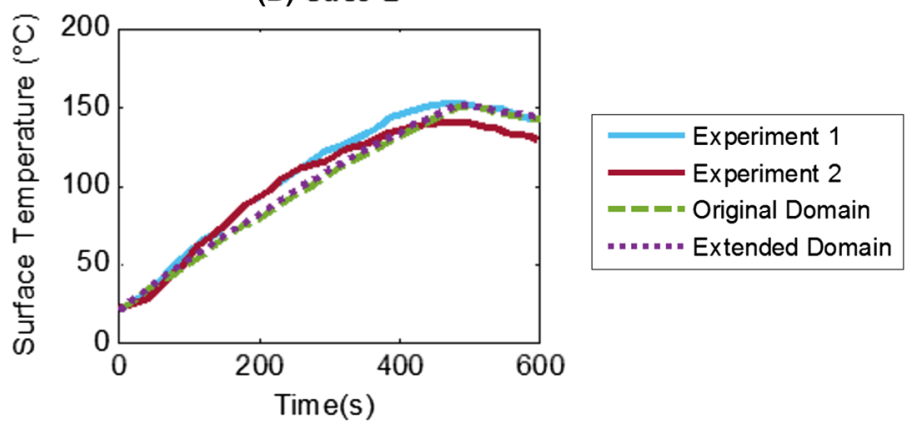

FIGURE 6 CFD computional domain comparison: A, case 1 and B, case 2 [Colour figure can be viewed at wileyonlinelibrary.com] 

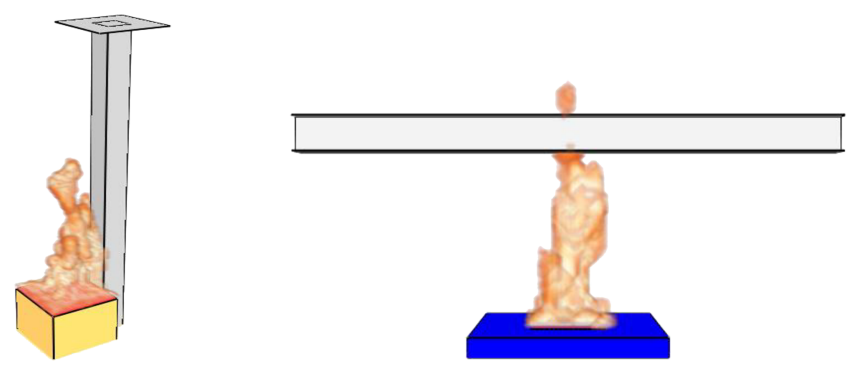

FIGURE 7 CFD simulation of A, case 1 and B, case 2 [Colour figure can be viewed at wileyonlinelibrary.com]

A FE mesh sensitivity study was conducted for case 1. Again, because of the similar nature of cases 1 and 2 and that the same element size was used for both cases, an additional mesh sensitivity study was not conducted for case 2 . The results of the FE mesh sensitivity study are presented in Figure 8. An element size of $d x=0.01 \mathrm{~m}$ and $d x=0.005 \mathrm{~m}$ was tested and compared. Figure $8 \mathrm{~A}$ presents the thermal results in the center of the front side of the column (closest to the fire) measured $400 \mathrm{~mm}$ from the base. Figure $8 \mathrm{~B}$ presents the displacement results in the center of the front side of the column (closest to the fire) measured $1440 \mathrm{~mm}$ from the base. The figures show that reducing the element size does not significantly impact the results of this study.

In the mechanical model for case 1 , the base of the column was fixed, and no mechanical loads were applied. For case 2, only a thermal analysis was performed. The user-subroutine DFLUX was used to apply the distributed non-uniform fluxes to the FE model. The thermal boundary conditions used for both cases are discussed in detail in the following sections.

\section{5 | HEAT TRANSFER PRINCIPLES}

In typical structural fire engineering problems, heat is generated by a fire and is transferred to the structural surface through radiation and convection. Radiation refers to thermal energy that travels through space by electromagnetic waves. Convection is heat transfer through to the movement of molecules within a fluid such as air. Radiation and convection are independent terms, and when computing heat transfer to a surface, they must be considered separately. ${ }^{16} \mathrm{~A}$ mixed boundary condition is the most common way to express the boundary condition in structural fire engineering applications. ${ }^{4}$ Equation (3) represents the total heat transfer to a surface with independent terms for radiative and convective heat transfer, where $\dot{q}_{\text {tot }}^{\prime \prime}$ is the total net heat flux $\left(\mathrm{W} / \mathrm{m}^{2}\right), \dot{a}_{\text {rad }}^{\prime \prime}$ is the net radiative heat flux, and $\dot{q}_{\text {con }}^{\prime \prime}$ is the convective heat flux. ${ }^{16}$

$$
\dot{\mathrm{q}}_{\mathrm{tot}}^{\prime \prime}=\dot{\mathrm{q}}_{\mathrm{rad}}^{\prime \prime}+\dot{\mathrm{q}}_{\mathrm{conv}}^{\prime \prime}
$$

Equation (4) defines the net radiation, where $\dot{q}_{a b s}^{\prime \prime}$ is the absorbed radiant heat $\left(\mathrm{W} / \mathrm{m}^{2}\right)$ and $\dot{q}_{\text {emi }}^{\prime \prime}$ is the emitted radiant heat $\left(\mathrm{W} / \mathrm{m}^{2}\right)$.

$$
\dot{\mathrm{q}}_{\mathrm{rad}}^{\prime \prime}=\dot{\mathrm{q}}_{\mathrm{abs}}^{\prime \prime}-\dot{\mathrm{q}}_{\mathrm{emi}}^{\prime \prime}
$$

Equation (5) defines the absorbed radiant heat where $\alpha$ is the absorptivity, $G$ is the irradiation, $\varepsilon$ is the surface emissivity, $\sigma$ is the Stefan-Boltzmann constant $\left(\mathrm{W} / \mathrm{m}^{2} \mathrm{~K}^{4}\right), T_{r}$ is the radiation temperature $(\mathrm{K})$, and $\dot{a}_{\text {inc }}^{\prime \prime}$ is the incident radiation $\left(\mathrm{W} / \mathrm{m}^{2}\right)$. The radiation temperature is the equilibrium temperature that an object will obtain if subjected to only constant radiation (no convection or conduction). ${ }^{16}$ Note that Equation (5) only holds true if $\alpha=\varepsilon$, which is true for a gray surface. All structural surfaces in this study were assumed to be gray surfaces, which is a standard assumption in the structural fire engineering field. A gray surface is a special case for when radiation exchange occurs between a small surface and a much larger surface (which is at a constant temperature) that completely surrounds the smaller surface. The surroundings could be a furnace or the walls of a room where the temperature of the surroundings is not equal to the temperature of the surface. ${ }^{17}$ This equation shows that the absorbed radiation is dependent on the incident radation. ${ }^{16}$

$$
\dot{\mathrm{q}}_{\mathrm{abs}}^{\prime \prime}=\alpha \mathrm{G}=\varepsilon \mathrm{G}=\varepsilon \sigma \mathrm{T}_{\mathrm{r}}^{4} \equiv \varepsilon \dot{\mathrm{q}}_{\mathrm{inc}}^{\prime \prime}
$$

Equation (6) defines emitted radiation where $T_{s}$ is surface temperature $(K)$. This equation shows that emitted radiation is governed by the surface temperature. ${ }^{16}$
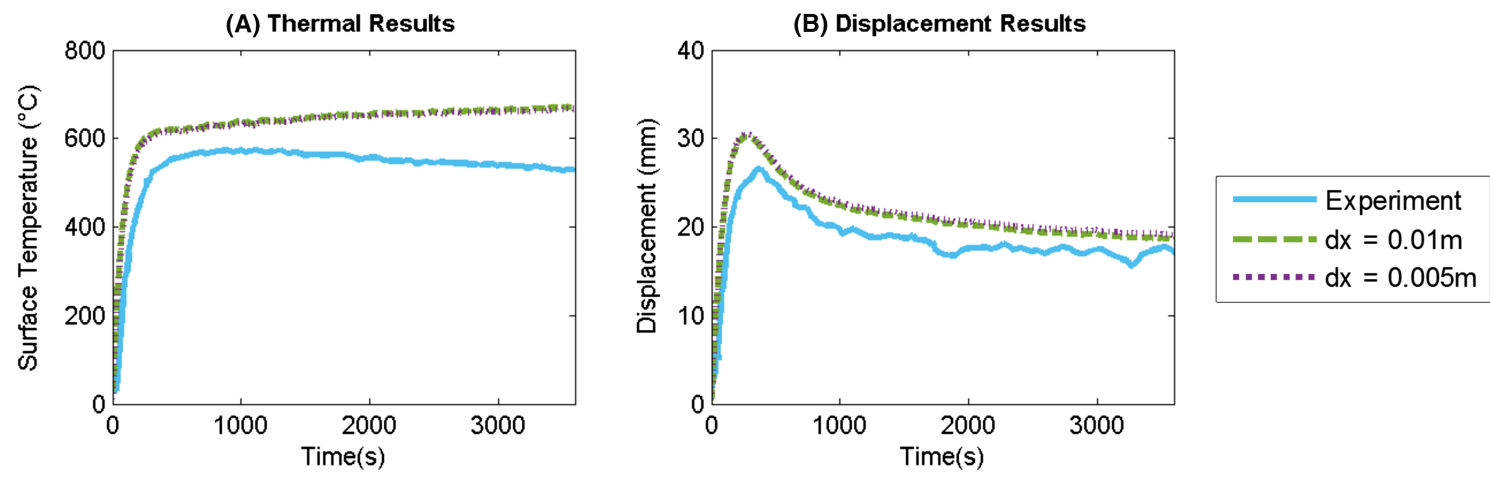

FIGURE 8 Finite element mesh sensitivity study: A, thermal results and B, displacement results [Colour figure can be viewed at wileyonlinelibrary.com] 


$$
\dot{\mathrm{q}}_{\mathrm{emi}}^{\prime \prime}=\varepsilon \sigma \mathrm{T}_{\mathrm{s}}^{4} .
$$

Equation (7) defines the convective heat transfer by convection, where $h$ is the heat transfer coefficient $\left(\mathrm{W} / \mathrm{m}^{2} \mathrm{~K}\right)$ and $T_{g}$ is gas temperature (K). This relationship shows that convective heat transfer is controlled by the temperature difference between gas temperature and surface temperature ${ }^{15}$.

$$
\dot{\mathrm{q}}_{\mathrm{conv}}^{\prime \prime}=\mathrm{h}\left(\mathrm{T}_{\mathrm{g}}-\mathrm{T}_{\mathrm{s}}\right) \text {. }
$$

Equations (3) to (7) can be combined to create Equation (8), which represents total heat transfer or net heat flux to a surface. ${ }^{16}$

$$
\dot{\mathrm{q}}_{\text {tot }}^{\prime \prime}=\varepsilon\left(\dot{\mathrm{q}}_{\text {inc }}^{\prime \prime}-\sigma \mathrm{T}_{\mathrm{s}}^{4}\right)+\mathrm{h}\left(\mathrm{T}_{\mathrm{g}}-\mathrm{T}_{\mathrm{s}}\right) .
$$

The adiabatic surface temperature (AST) is the temperature of a surface where heat is not absorbed or emitted, and it is a weighted average of the radiation temperature and the gas temperature. ${ }^{4}$ The weighting is dependent on the surface emissivity and the heat transfer coefficent. AST will be closer the the gas temperature for a high heat transfer coefficient, and the AST will be closer to the radiation temperature for a low heat transfer coefficent. ${ }^{16}$ AST is independent of surface temperature. ${ }^{4}$ Equation (9) presents the defining relation for adiabatic surface temperature, where $T_{A S T}$ is the adiabatic surface temperature $(K)$.

$$
\varepsilon\left(\dot{\mathrm{q}}_{\text {inc }}^{\prime \prime}-\sigma \mathrm{T}_{\text {AST }}^{4}\right)+\mathrm{h}\left(\mathrm{T}_{\mathrm{g}}-\mathrm{T}_{\mathrm{AST}}\right)=0 .
$$

Equation (10) represents the total heat transfer to a surface based on adiabatic surface temperature. The full derivation for this equation can be found in the literature. ${ }^{16}$

$$
\dot{\mathrm{q}}_{\text {tot }}^{\prime \prime}=\varepsilon \sigma\left(\mathrm{T}_{\mathrm{AST}}^{4}-\mathrm{T}_{\mathrm{S}}^{4}\right)+\mathrm{h}\left(\mathrm{T}_{\mathrm{AST}}-\mathrm{T}_{\mathrm{S}}\right) .
$$

Note that Equations (8) and (10) are theoretically equivalent to each other. Care should be taken when comparing Equations (8) and (10) using output data from FDS. These equations are equivalent to each other when the data used are measured at a specific point in time. FDS by default outputs time-averaged data.

\section{6 | ANAYLSIS OF SOLID CONDUCTION MODELS}

\section{1 | Solid temperature determined by FE analysis}

Heat flux predicted by incident radiative heat flux and gas temperature is presented in Equation (8) and is the most traditional representation. It is also the most computationally expensive method considered in this study; it requires at least two spatially and temporally variable parameters from the CFD simulation to be transferred to the FE model, namely, the incident radiative heat flux (FDS DEVC = "Incident Heat Flux") and gas temperature (FDS DEVC = "Gas Temperature"). To reduce the computational expense of determining the net heat flux, Equation (10) was developed ${ }^{4}$ to calculate the net heat flux based on adiabatic surface temperature (AST). This method of representing the net heat flux is computationally efficient because it only requires one variable parameter from the CFD code to be transferred to the FE analysis, in this case, adiabatic surface temperature (FDS DEVC = "Adiabatic Surface Temperature"). Note that because Equations (8) and (10) are theoretically equal, it follows that the results from calculating heat flux based on incident radiative heat flux and gas temperature or adiabatic surface temperature are also equal. This method uses the FE prediction of solid temperature $\left(T_{5}\right)$ in Equations (8) and (10). This solid temperature model will be referred to as FEM in Section 9.

\section{2 | Solid temperature determined by FDS}

The heat flux predicted by the CFD code is also a computationally efficient approach for determining the net heat flux to a surface; at most, it relies on the inclusion of only one spatially and temporally varying parameter, net heat flux (FDS DEVC = "Net Heat Flux"). The CFD code used in this study, $\mathrm{FDS},{ }^{15}$ calculates the total net heat flux using Equation (8). It should be noted that this approach is not used in practice as it depends on the CFD simulation to predict surface temperature $\left(T_{s}\right)$, which FDS was not designed to do. This solid temperature model will be referred to as CFD in the results section of this paper.

\section{7 | ANALYSIS OF HEAT TRANSFER COEFFICIENT}

The heat transfer coefficient is an important parameter used to calculate the convective heat flux as shown in Equation (7). As previously discussed, the literature recommends a variety of values for the heat transfer coefficient.

\section{1 | Heat transfer coefficient as $9 \mathrm{~W} / \mathrm{m}^{2} \mathrm{~K}$}

This value is recommended for use by one study ${ }^{7}$ for calculating the boundary condition of a coupled CFD-FE model of an isolated structural member subjected to a localized fire. This approach for representing the heat transfer coefficient is computationally efficient because it is a constant value.

\subsection{Heat transfer coefficient as $35 \mathrm{~W} / \mathrm{m}^{2} \mathrm{~K}$}

The value of $35 \mathrm{~W} / \mathrm{m}^{2} \mathrm{~K}$ is recommended by Eurocode ${ }^{5}$ for use when a more detailed approach is unavailable. It is implemented by one study ${ }^{6}$ for modeling a vehicle fire in a parking structure. This method is also computationally efficient because it employs a constant value.

\section{3 | Spatially and temporally varying heat transfer coefficient}

This approach requires using a nonconstant value for the heat transfer coefficient calculated by the CFD analysis. The CFD code used in this 
study, FDS, determines the heat transfer coefficient based on the equation as follows,

$$
h=\max \left[C\left|T_{g}-T_{s}\right|^{\frac{1}{3}}, k \frac{k}{L} N u\right]
$$

where $C$ is the empirical coefficient for natural convection, $k$ is conductivity $(\mathrm{W} / \mathrm{m}-\mathrm{K}), \mathrm{L}$ is characteristic lengh $(\mathrm{m})$, and $\mathrm{Nu}$ is the Nusselt number.

Silva et $\mathrm{al}^{8}$ recommend the use of a variable heat transfer coefficient for a coupled CFD-FE model. Furthermore, Wickstrom ${ }^{4}$ discourages the use of a constant heat transfer coefficent in fire protection engineering because the heat transfer coefficient can be highly dependent on gas temperature and surface temperature, which can vary significantly, especially localized fire scenarios. This method is the most computionally expensive approach to modeling the heat transfer coefficent because it requires the inclusion of an additional spatially and temporally variable parameter from the CFD simultaion.

\section{I ANALYSIS OF SURFACE EMISSIVITY}

The emissivity of a surface is defined as the ratio between the radiative heat absorbed by a surface to that absorbed by a blackbody surface. A blackbody is an idealized surface that absorbs all incident radiation. Emissivity is related to the calculation of the net radiative heat flux as shown in Equations (5) and (6). Both methods described

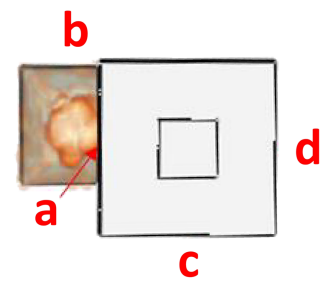

(A) Temperature measurement locations for case 1

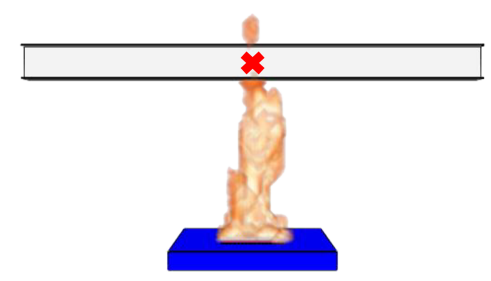

(B) Temperature measurement location for case 2
FIGURE 9 Temperature measurement locations for A, case 1 and B, case 2 [Colour figure can be viewed at wileyonlinelibrary.com]

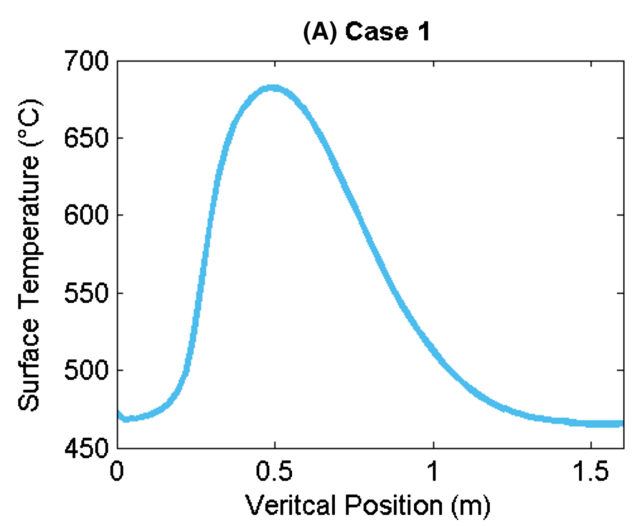

below recommend using a constant value for the surface emissivity; therefore, they both have the same computational expense.

\section{1 | Emissivity of steel as 0.7}

The Eurocode 5 suggests using a value of 0.7 for traditional calculations of steel exposed to fire.

\section{2 | Emissivity of steel as 0.9}

A value of 0.9 as the emissivity of steel is used by one study ${ }^{9}$ for a CFD-FE model of a column subjected to a localized fire.

\section{9 | RESULTS AND DISCUSSION}

Figure $9 A, B$ visually displays where the temperature measurements were recorded in relation to the fire for the following results for cases 1 and 2 , respectively.

\section{1 | Discussion of solid temperature models}

Equations (8) and (10) are theoretically equivalent to each other, and therefore, the results from utilizing net heat flux calculated from incident radiative heat flux and gas temperature will be the same as the results from utilizing net heat flux calculated from adiabatic surface temperature. The results from both heat flux assumptions will be labeled as FEM in the results because they both use the FE prediction of surface temperature $\left(T_{\mathrm{s}}\right)$. The results when utilizing net heat flux calculated from the CFD code will be different because it relies on the CFD prediction of surface temperature $\left(T_{s}\right)$. FDS, the CFD code used in this study, employs only a 1D conduction model, which will result in errors for the case of large thermal gradients that occur due to localized fires. To demonstrate the importance of using a 3D conduction model for coupled CFD-FE localized fire models, Figure $10 \mathrm{~A}, \mathrm{~B}$ displays the spatially varying surface temperatures that occur through the center of the front surface of the column (closest to the fire) in case 1 at $3600 \mathrm{~s}$ (end of simulation time) and the center of the bottom flange of the beam in case 2 at $600 \mathrm{~s}$ (end of simulation

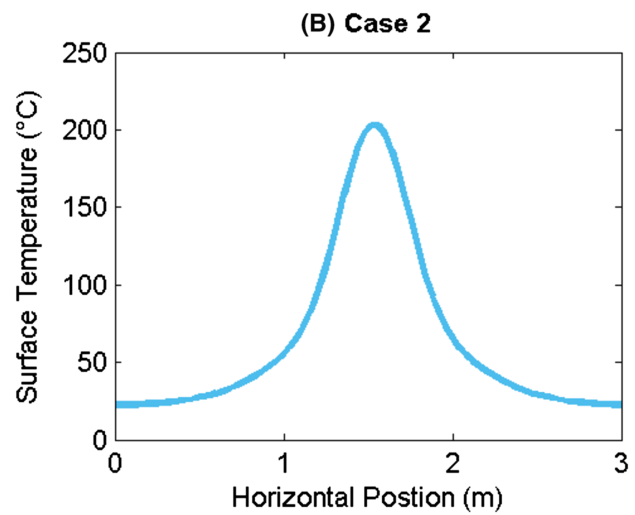

FIGURE 10 Spatially varying temperature analysis: A, case 1 and B, case 2 [Colour figure can be viewed at wileyonlinelibrary.com] 
time), respectively. Figure $10 \mathrm{~A}$ shows that the front surface temperature of the column varies from approximately $466^{\circ} \mathrm{C}$ at the top of the column to over $680^{\circ} \mathrm{C}$ at $0.45 \mathrm{~m}$ measured from the base, which is approximately $0.2 \mathrm{~m}$ above the burner. Figure $10 \mathrm{~B}$ shows the surface temperatures on the bottom flange of the beam vary from approximately $25^{\circ} \mathrm{C}$ at both ends to over $200^{\circ} \mathrm{C}$ in the center of the beam, which is located directly over the pool fire. Both cases demonstrate a range of temperatures of approximately $200^{\circ} \mathrm{C}$ on a single surface.

Figure 11 displays the temperature results considering a CFD solid temperature model for case 1 . The FEM results are not presented here because ABAQUS was not able to properly model the cavity heat transfer. Figure $11 \mathrm{~A}$ displays the surface temperature results on the front surface (facing the fire) at $0.4 \mathrm{~m}$, and Figure 11B shows the temperature results for the corner of the column, in between the front and side surface, at $0.4 \mathrm{~m}$. Figure $11 \mathrm{C}, \mathrm{D}$ displays the temperature results for the side and back surfaces of the column, respectively, at $0.6 \mathrm{~m}$. On the cross-section level, measurements for temperature on the front, side, and back surfaces were recorded from the center of the respective column face. A surface emissivity of 0.9 and a variable heat transfer coefficient predicted by the CFD code were used for both cases in this section.

Figure 12 displays the surface temperature results for case 2 considering varying solid temperature predictions. Temperatures were recorded at mid-span and mid-web of the beam.

Figure 13 displays the lateral displacement results along the length of the column in case 1 considering a CFD solid temperature model. Again, The FEM results are not presented here because ABAQUS was not able to properly model the cavity heat transfer. Figure 13AD shows the displacement results recorded at 1.44, 1.225, 0.925,

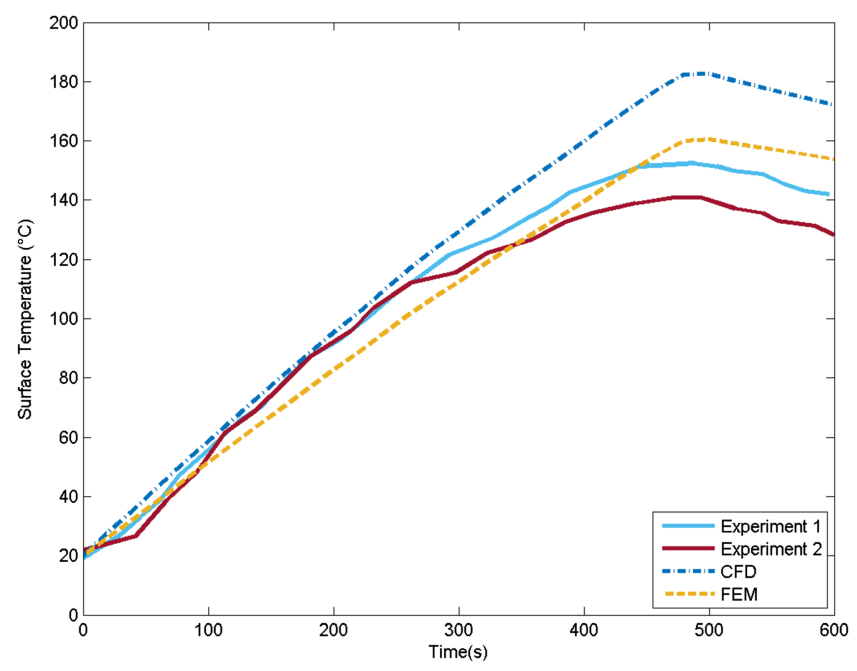

FIGURE 12 Thermal results for case 2 based on varying solid temperature models [Colour figure can be viewed at wileyonlinelibrary.com]

and $0.775 \mathrm{~m}$, respectively, along height of the column, measured from the base. On the cross-section level, measurements for displacement were recorded in the center of the front face of the column.

Generally, the thermal results presented in Figures 11 and 12 demonstrate that using the CFD prediction of solid temperatures to calculate heat flux resulted in higher predicted temperatures. The thermal results for case 1 presented in Figure 11 show that using the CFD solid temperature model overpredicted the temperatures on the front surface and more accurately predicted temperatures on the side and back surfaces. The thermal results for case 2 presented in Figure 12
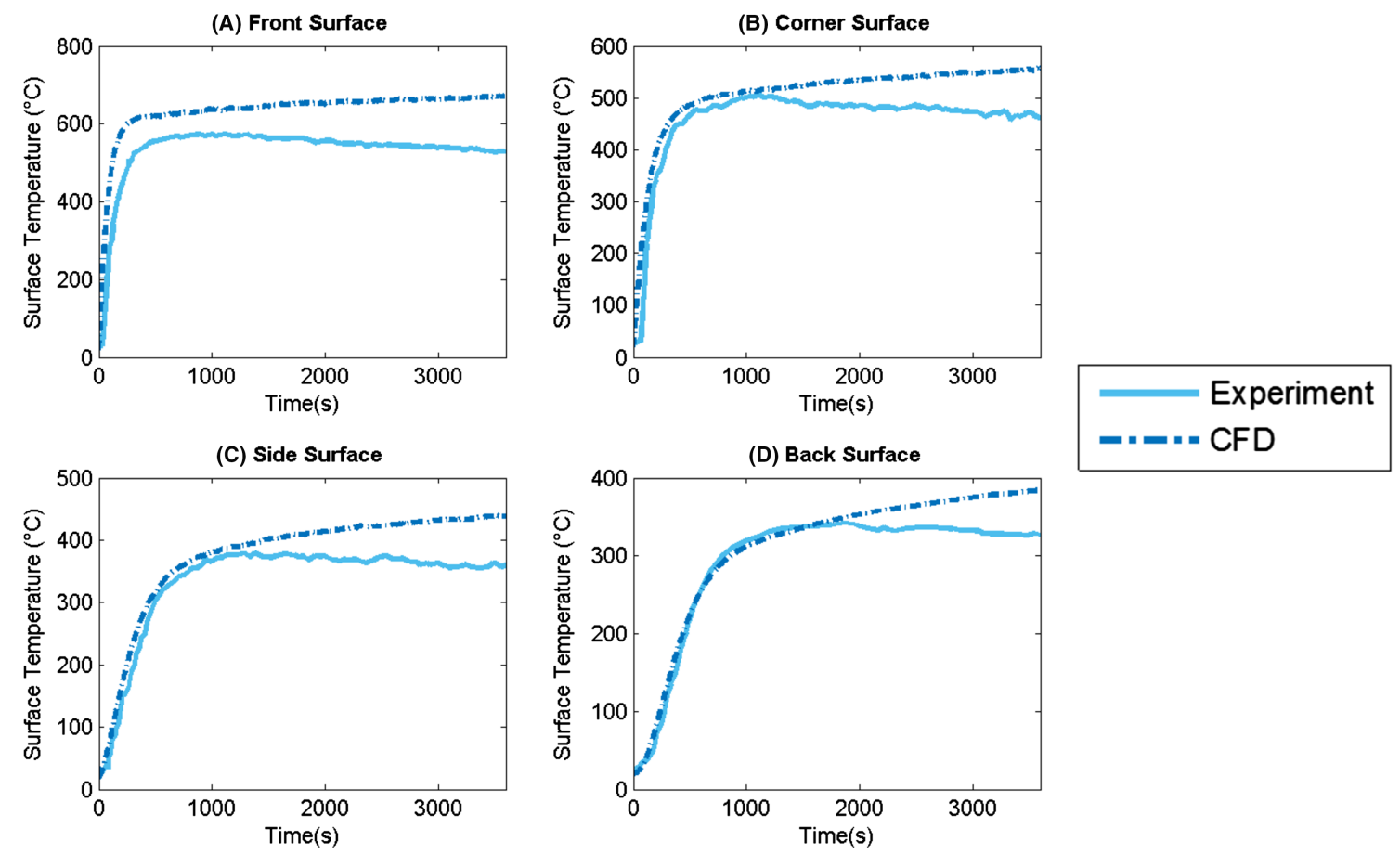

FIGURE 11 Thermal results for case 1 considering a CFD solid temperature model: A, front surface; B, corner surface; C, side surface; D, back surface [Colour figure can be viewed at wileyonlinelibrary.com] 


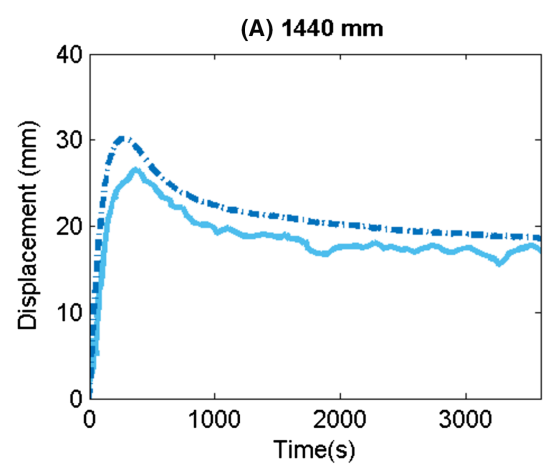

(C) $925 \mathrm{~mm}$

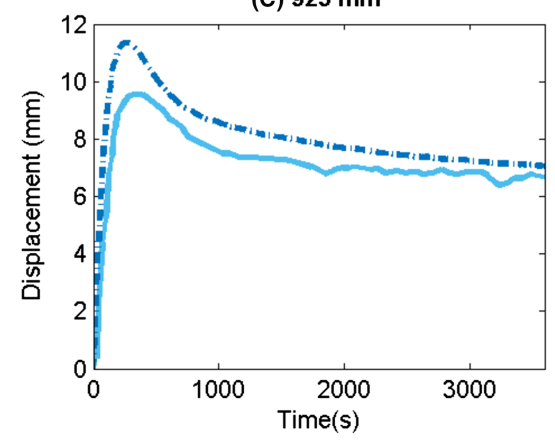

(B) $1225 \mathrm{~mm}$

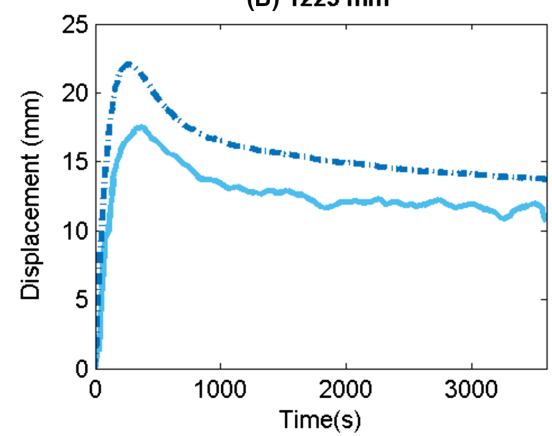

(D) $775 \mathrm{~mm}$

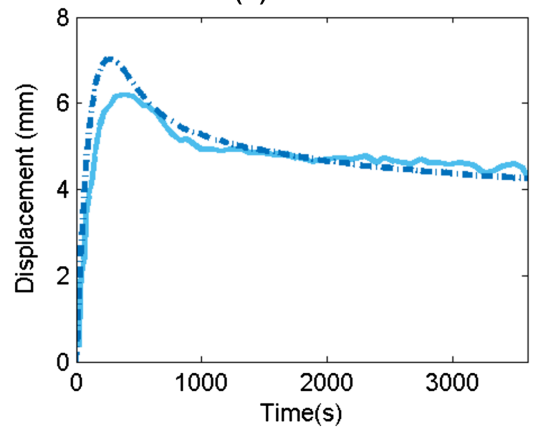

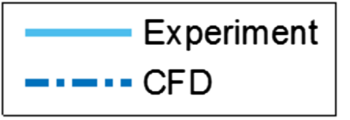

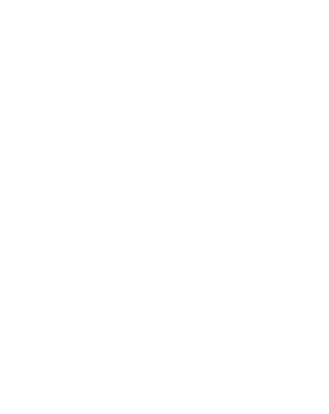

FIGURE 13 Displacement results for case 1 considering a CFD solid temperature model: A, 1440 mm; B, 1225 mm; C, 925 mm; D, 775 mm [Colour figure can be viewed at wileyonlinelibrary.com]

show that using the FEM calculation of solid temperature resulted in a lower and more accurate prediction of the surface temperature; the CFD calculation of solid temperature overpredicted the temperature in this case.

Figure 13 displays the displacement predictions for case 1 . The CFD solid temperature model slightly overpredicted the displacements, especially earlier in the simulations. As the simulation progressed, the predicted displacements more accurately modeled the experimental displacements, except for the back surface of the column. The displacement prediction on the back surface of the column was slightly underpredicted.

Overall, the FEM solid temperature model is a more accurate representation of solid temperatures in a localized fire scenario and was able to better predict surface temperatures close to the flame, as shown in case 2 . Therefore, this study recommends using the FEM solid temperature model when possible.

\subsection{Comparison of heat transfer coefficient}

Figure 14 displays the temperature results for varying heat transfer coefficients in case 1 . Figure $14 \mathrm{~A}$ displays the surface temperature results on the front surface (facing the fire) at $0.4 \mathrm{~m}$, and Figure 14B shows the temperature results for the corner of the column, in between the front and side surfaces, at $0.4 \mathrm{~m}$. Figure 14C,D displays the temperature results for the side and back surfaces of the column, respectively, at $0.6 \mathrm{~m}$. On the cross-section level, measurements for temperature on the front, side, and back surfaces were recorded from the center of the respective column face. A surface emissivity of 0.9 and surface temperature predicted by the CFD code were used for both cases in this section.

Figure 15 displays the surface temperature results for case 2 considering varying heat transfer coefficient assumptions. Temperatures were recorded at mid-span and mid-web of the beam.

Figure 16 displays the lateral displacement results along the length of the column in case 1 considering the varying heat transfer coefficient assumptions. Figure 16A-D shows the displacement results recorded at $1.44,1.225,0.925$, and 0.775 , respectively, along height of the column, measured from the base. On the cross-section level, measurements for displacement were recorded in the center of the front face of the column.

The thermal results for the different heat transfer coefficient assumptions show that the predicted temperatures can vary significantly based on the employed assumption. A heat transfer coefficient of $35 \mathrm{~W} / \mathrm{m}^{2} \mathrm{~K}$ significantly overpredicted the temperatures of the beam in case 2 as seen in Figure 15. In case 1, a heat transfer coefficient of $35 \mathrm{~W} / \mathrm{m}^{2} \mathrm{~K}$ overpredicted the temperatures on the front and corner surface of the column, accurately predicted the temperatures on the side surface, and underpredicted temperatures on the back surface. Temperatures were overpredicted on the front and corner surfaces because these surfaces are closest to the fire where gas temperatures are the highest, so the convective heat transfer to these surfaces is heating the column, and a large heat transfer coefficient overpredicted this behavior. On the back surface, furthest from the fire, the gas temperatures are lower, and the convective heat transfer is working to cool the back surface, which resulted in underpredicted 

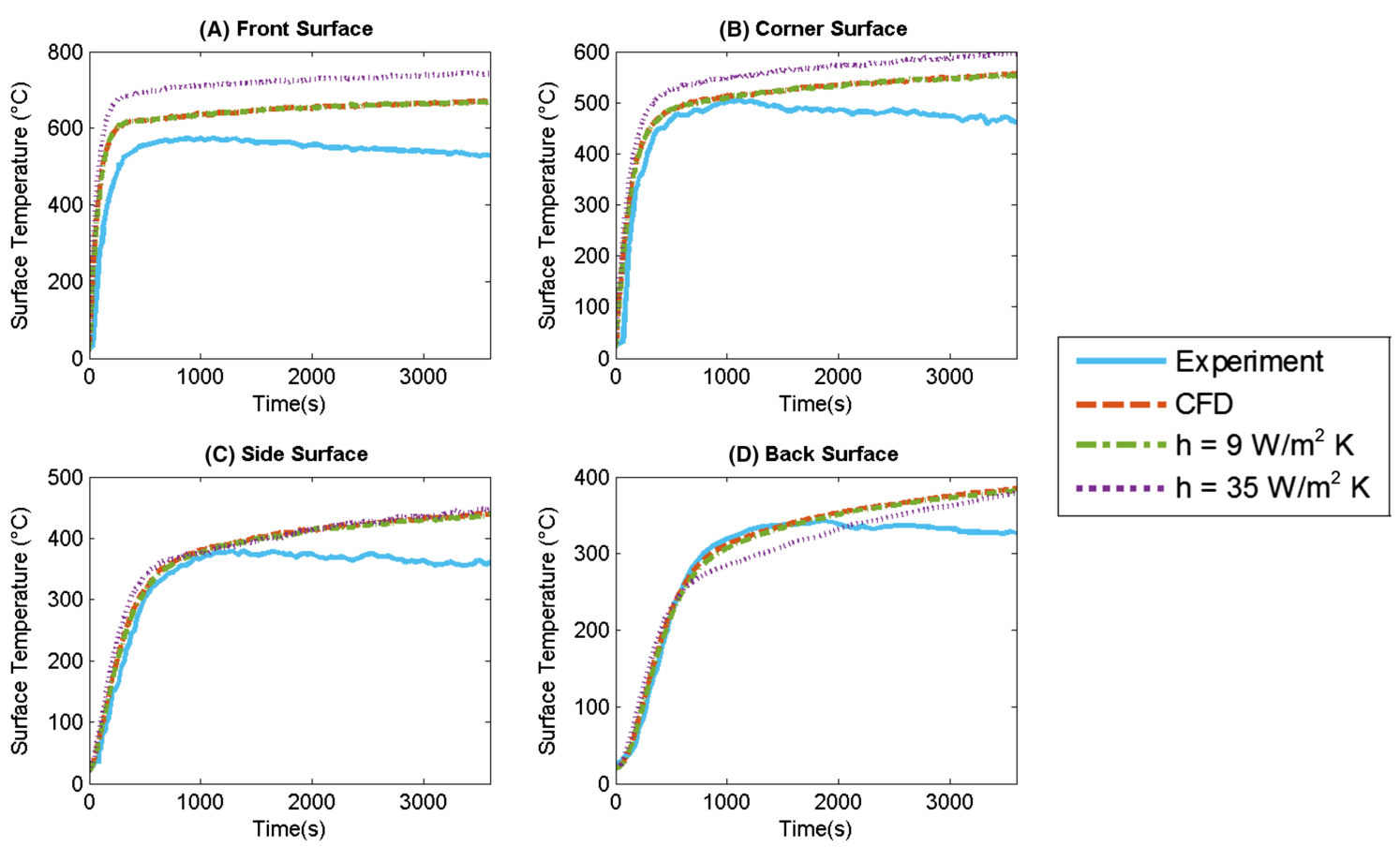

FIGURE 14 Thermal results for case 1 based on varying heat transfer coefficient (h) assumptions: A, front surface; B, corner surface; C, side surface; D, back surface [Colour figure can be viewed at wileyonlinelibrary.com]

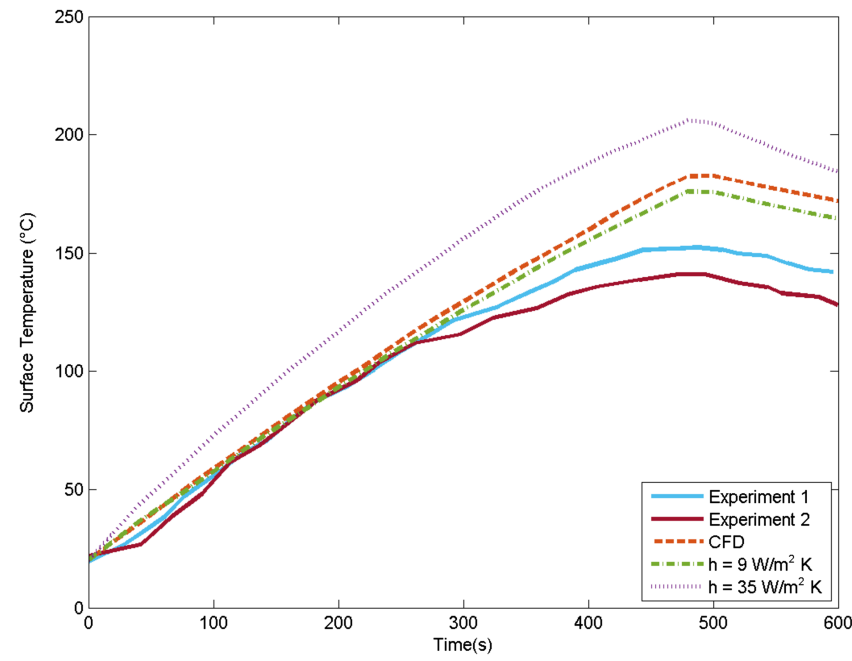

FIGURE 15 Thermal results for case 2 based on varying heat transfer coefficient $(\mathrm{h})$ assumptions [Colour figure can be viewed at wileyonlinelibrary.com]

temperatures when the convective heat flux is weighted more heavily by a larger heat transfer coefficient. In case 1 , assuming the heat transfer coefficient as equal to $9 \mathrm{~W} / \mathrm{m}^{2} \mathrm{~K}$ resulted in slightly lower column temperatures than assuming a heat transfer coefficient predicted by the CFD code as seen in Figure 14. In case 2, there was an opposite effect on the thermal response. The heat transfer coefficient calculated by the CFD code resulted in slightly lower predicted temperatures than the temperatures predicted by a heat transfer coefficient of $9 \mathrm{~W} / \mathrm{m}^{2} \mathrm{~K}$, which can be seen in Figure 15.
The displacement results seen in Figure 16 show that a heat transfer coefficient of $9 \mathrm{~W} / \mathrm{m}^{2} \mathrm{~K}$ predicted slightly higher displacements while a variable heat transfer coefficient from the CFD code predicted lower and more accurate displacements. A heat transfer coefficient of 35 $\mathrm{W} / \mathrm{m}^{2} \mathrm{~K}$ significantly overpredicted the displacement results due to the artificially large temperature gradient it predicted within the cross section of the column.

Figure 17A shows the heat transfer coefficient predicted by the CFD code along the height of the column for case 1 at $1600 \mathrm{~s}$ (half of the simulation time). Along the front surface of the column, there are high levels of nonuniformity predicted, with a minimum heat transfer coefficient of $1.21 \mathrm{~W} / \mathrm{m}^{2} \mathrm{~K}$ and a maximum heat transfer coefficient of $11.65 \mathrm{~W} / \mathrm{m}^{2} \mathrm{~K}$. Along the back surface of the column, there was nonuniformity as well, but to a smaller degree. The back surface had a minimum heat transfer coefficient of $2.75 \mathrm{~W} / \mathrm{m}^{2} \mathrm{~K}$ and a maximum heat transfer coefficient of $7.93 \mathrm{~W} / \mathrm{m}^{2} \mathrm{~K}$. Figure $17 \mathrm{~B}$ shows the heat transfer coefficient along the length of the beam predicted by the CFD code for case 2 at $300 \mathrm{~s}$ (half the simulation time). Along the bottom flange, high nonuniformity of the heat transfer coefficient can be seen. The minimum predicted heat transfer coefficient, located on the far edge of the beam, is 1.44 $\mathrm{W} / \mathrm{m}^{2} \mathrm{~K}$, and the maximum predicted heat transfer coefficient, located where the flame in impinging on the bottom surface, is $9.26 \mathrm{~W} / \mathrm{m}^{2} \mathrm{~K}$.

These results signify that the heat transfer coefficient for localized fires cannot be accurately represented by a single constant value. Different localized fire scenarios will result in different values for the heat transfer coefficient. There can be significant variation in the heat transfer coefficient over the entire structural member. Therefore, a spatially and temporally variable heat transfer coefficient should be included in coupled CFD-FE analyses when possible. If using a variable 


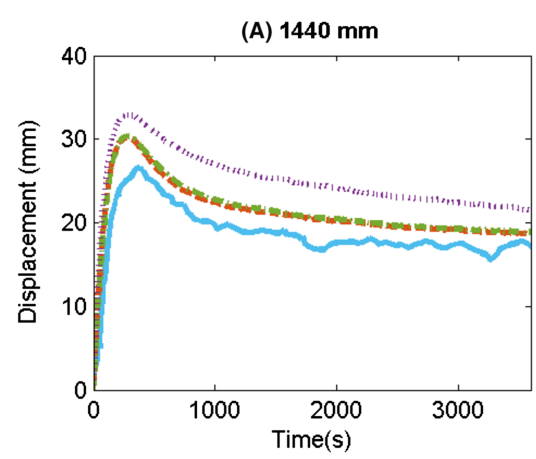

(C) $925 \mathrm{~mm}$

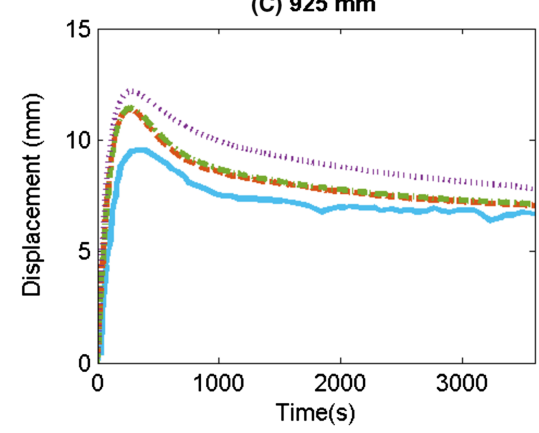

(B) $1225 \mathrm{~mm}$

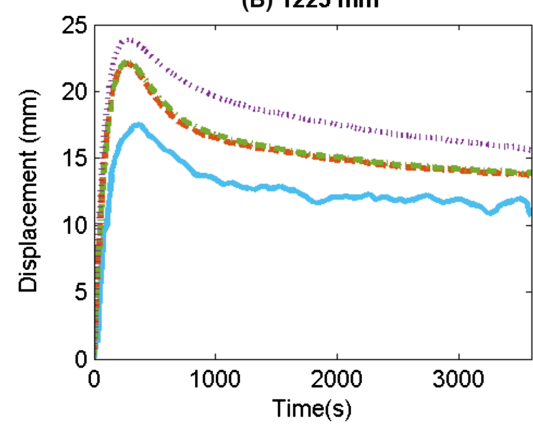

(D) $775 \mathrm{~mm}$

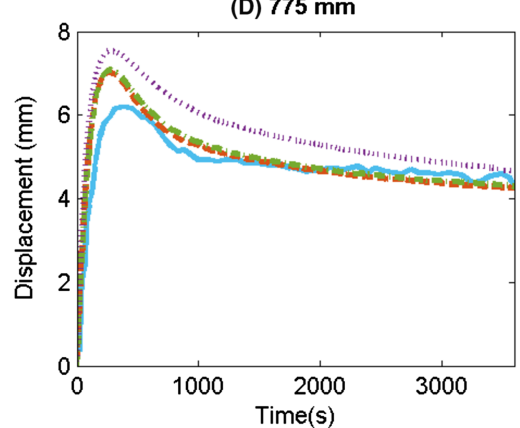

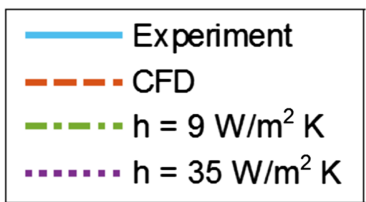

FIGURE 16 Displacement results for case 1 based on varying heat transfer coefficient (h) assumptions: A, 1440 mm; B, 1225 mm; C, 925 mm; D, $775 \mathrm{~mm}$ [Colour figure can be viewed at wileyonlinelibrary.com]

(A) Case 1

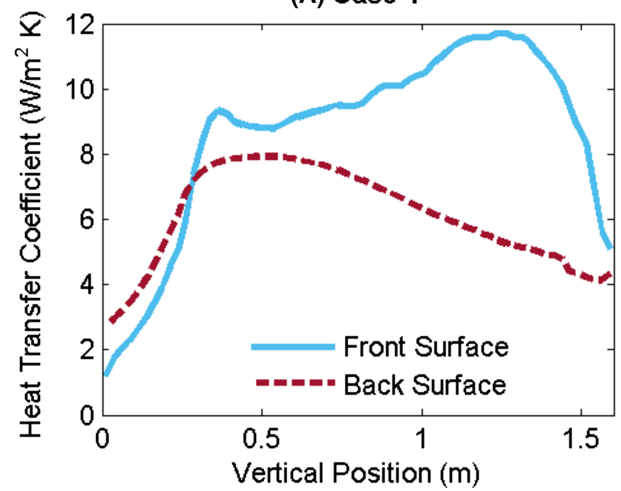

(B) Case 2

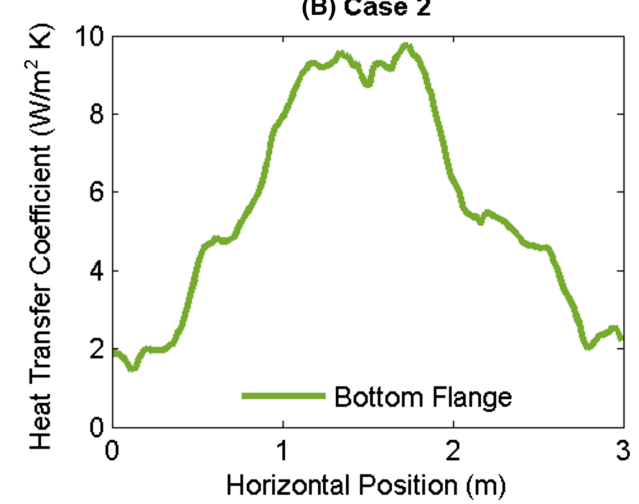

FIGURE 17 Heat transfer coefficients predicted by the CFD code: A, case 1 and B, case 2 [Colour figure can be viewed at wileyonlinelibrary.com]

heat transfer coefficient is not possible, based on the results of the cases studied here, a constant value of $9 \mathrm{~W} / \mathrm{m}^{2} \mathrm{~K}$ should be used when modeling a localized fire on an isolated structural member.

\section{3 | Comparison of surface emissivity}

Figure 18 displays the temperature results for varying emissivity assumptions in case 1. Figure 18A displays the surface temperature results on the front surface (facing the fire) at $0.4 \mathrm{~m}$, and Figure $18 \mathrm{~B}$ shows the temperature results for the corner of the column, in between the front and side surfaces, at $0.4 \mathrm{~m}$. Figure 18C,D displays the temperature results for the side and back surfaces of the column at $0.6 \mathrm{~m}$, respectively. On the cross-section level, measurements for temperature on the front, side, and back surfaces were recorded from the center of the respective column face. A variable heat transfer coefficient and surface temperature predicted by the CFD code were used for both cases in this section.

Figure 19 displays the surface temperature results for case 2 considering varying surface emissivity assumptions. Temperatures were recorded at mid-span and mid-web of the beam.

Figure 20 displays the lateral displacement results along the length of the column in case 1 considering the various emissivity assumptions. Figure 20A-D shows the displacement results recorded at 1.44, 1.225, 0.925 , and $0.775 \mathrm{~m}$, respectively, along height of the column, measured from the base. On the cross-section level, measurements for displacement were recorded in the center of the front face of the column.

In both cases, the higher emissivity value resulted in higher predicted surface temperatures as expected, shown in Figures 18 and 

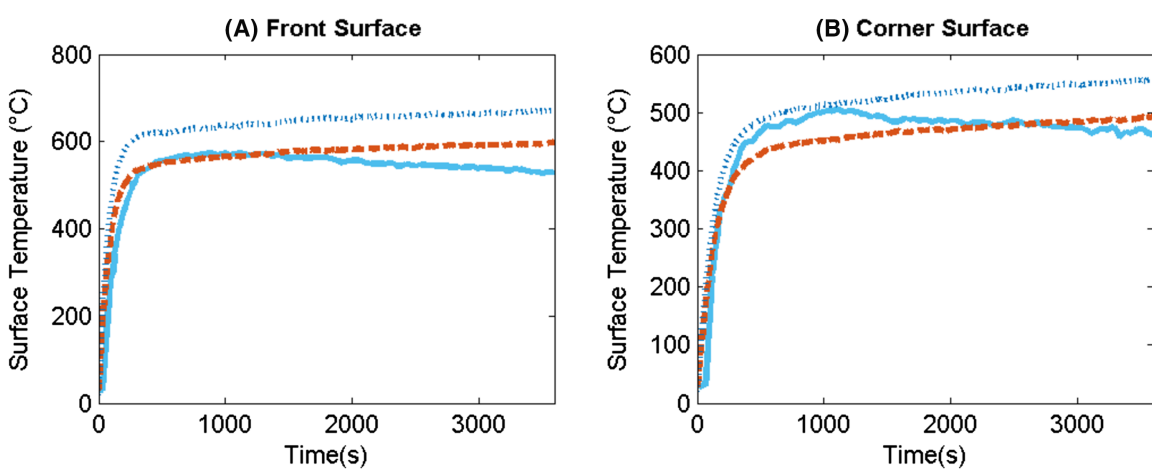

(C) Side Surface

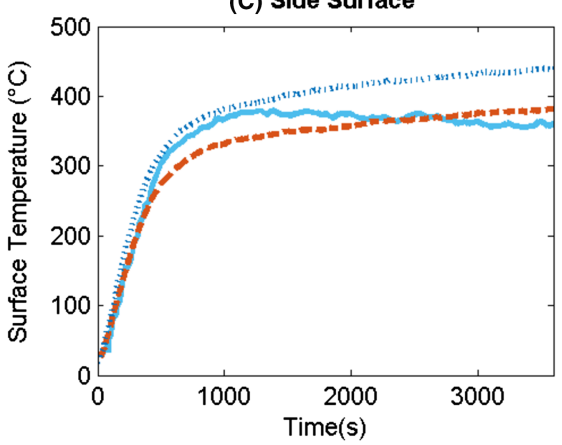

(D) Back Surface

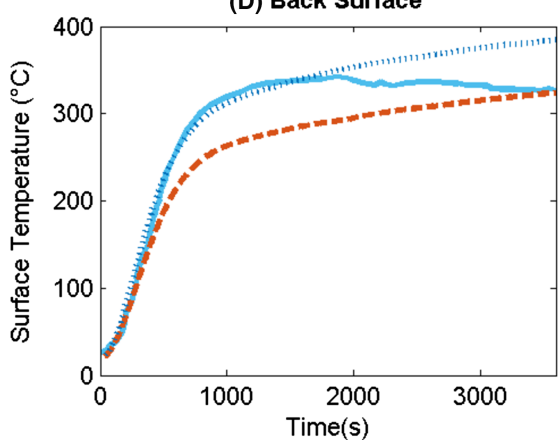

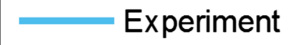

$---\mathrm{e}=0.7$

$\because \cdots \mathrm{e}=0.9$

FIGURE 18 Thermal results for case 1 based on varying emissivity (e) assumptions: A, front surface; B, corner surface; C, side surface; D, back surface [Colour figure can be viewed at wileyonlinelibrary.com]

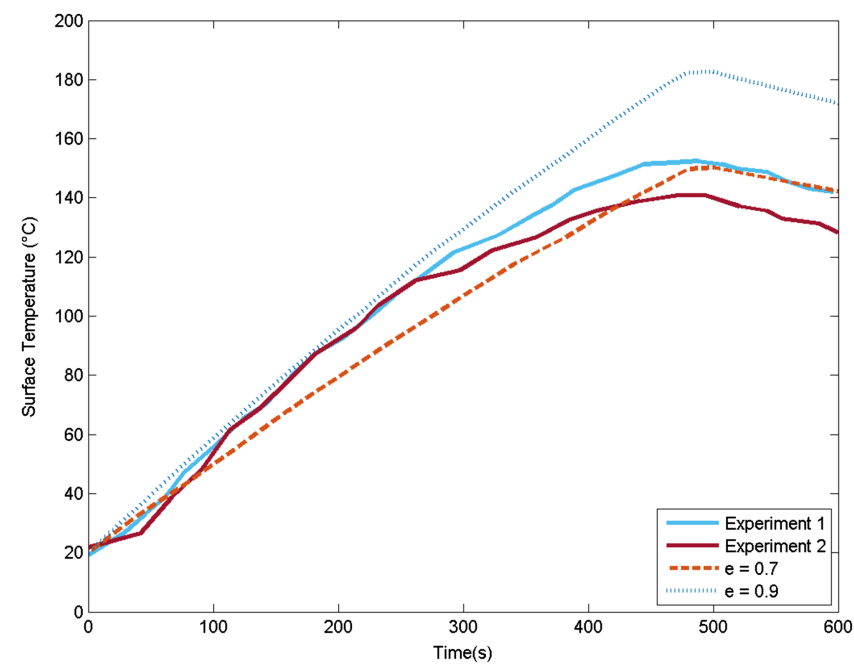

FIGURE 19 Thermal results for case 2 based on varying emissivity (e) assumptions [Colour figure can be viewed at wileyonlinelibrary.com]

19. In case 1 , an emissivity of 0.7 accurately predicted the temperatures on the front surface of the column but underpredicted temperatures on the back surface of the column, or the surface of the column farthest from the flame. For case 2 , where the only recorded temperatures were close to the flame, the emissivity of 0.7 more accurately modeled the temperature.

The displacement results displayed in Figure 20 show that the emissivity of 0.7 resulted in similar displacement predictions as using an emissivity of 0.9 . In the beginning of the simulation, an emissivity of 0.7 predicted lower displacements than an emissivity of 0.9 but as the simulation progressed, an emissivity of 0.7 predicted slightly higher displacement values.

Both emissivity assumptions resulted in similar displacement predictions, but an emissivity of 0.9 was able to more accurately predict the temperature of the column. Therefore, in this study, using an emissivity of 0.9 for localized fire scenarios is recommended as a conservative measure.

\subsection{Comparison of heat transfer coefficient and surface emissivity}

Figure 21 presents a comprehensive representation of various boundary condition assumptions for case 2 . Figure 21 displays the surface temperature results for case 2 considering varying heat transfer coefficient and surface emissivity assumptions. Temperatures were recorded at mid-span and mid-web of the beam.

Figure 21 shows that an emissivity of 0.7 always predicted lower temperatures than the corresponding emissivity of 0.9 results, which is expected. The results for a heat transfer coefficient predicted by the CFD code and a heat transfer coefficient equal to $9 \mathrm{~W} / \mathrm{m}^{2} \mathrm{~K}$ resulted in lower predicted temperatures than $35 \mathrm{~W} / \mathrm{m}^{2} \mathrm{~K}$ regardless of the emissivity during the heating phase of beam. The heating phase of the beam ends at approximately 492 seconds after the fuel burns out. During the cooling phase, the temperature prediction for an emissivity of 0.7 and a heat transfer coefficient equal to $35 \mathrm{~W} / \mathrm{m}^{2} \mathrm{~K}$ cools at a faster rate (due to the increased magnitude of convection), and the simulation ends with this boundary condition assumption resulting in a slightly lower temperature than predicted by assuming an 
(A) $1440 \mathrm{~mm}$

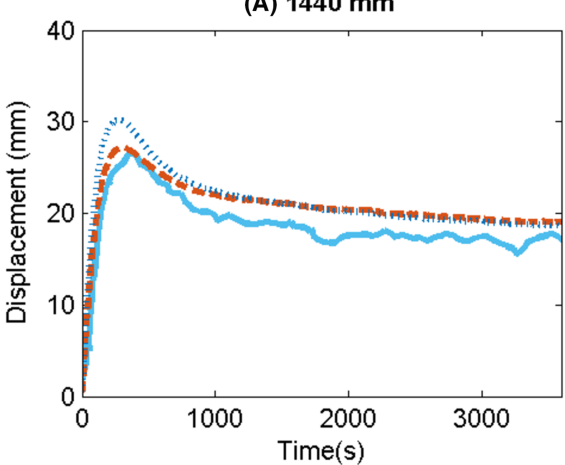

(C) $925 \mathrm{~mm}$

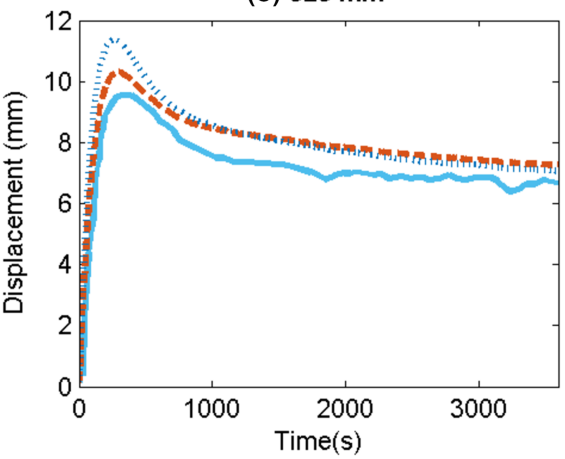

(B) $1225 \mathrm{~mm}$

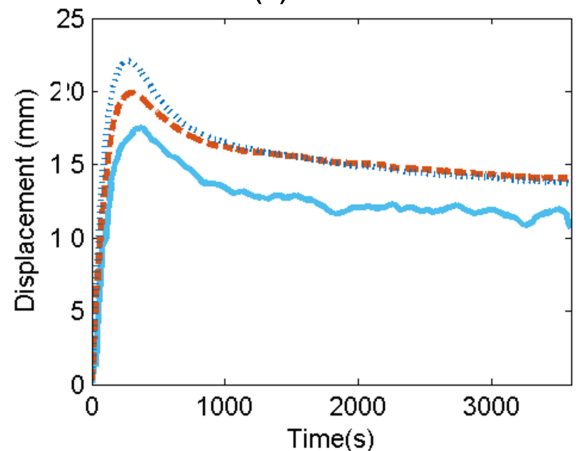

(D) $775 \mathrm{~mm}$

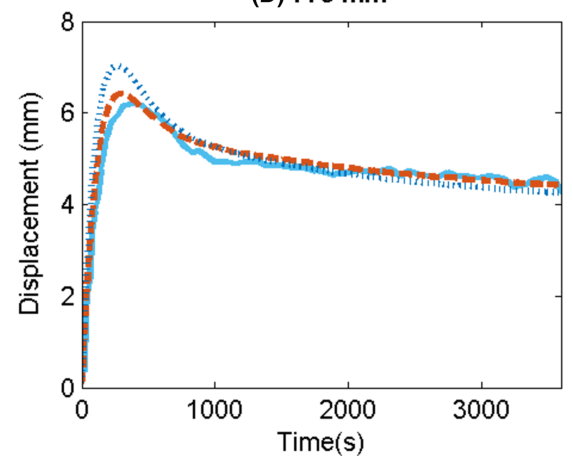

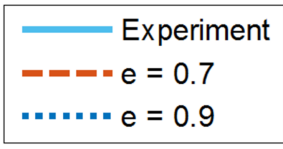

$\ldots+\ldots=0.9$

FIGURE 20 Displacement results for case 1 based on varying emissivity (e) assumptions: A, 1440 mm; B, 1225 mm; C, 925 mm; D, 775 mm [Colour figure can be viewed at wileyonlinelibrary.com]

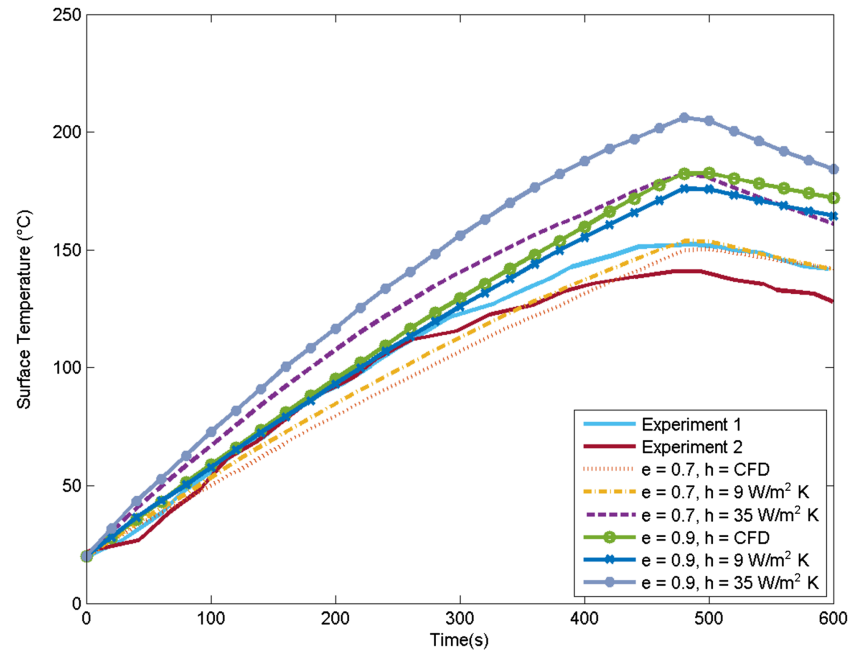

FIGURE 21 Thermal results for case 2 based on varying heat transfer coefficient (h) and emissivity (e) assumptions [Colour figure can be viewed at wileyonlinelibrary.com]

emissivity of 0.9 and a heat transfer coefficient predicted by the CFD code or equal to $9 \mathrm{~W} / \mathrm{m}^{2} \mathrm{~K}$. Overall, a modeling assumption of surface emissivity equal to 0.7 , and a heat transfer coefficient predicted by the CFD code resulted in the lowest predicted temperatures, while a modeling assumption of surface emissivity equal to 0.9 and a heat transfer coefficient equal to $35 \mathrm{~W} / \mathrm{m}^{2} \mathrm{~K}$ resulted in the highest predicted surface temperatures.
TABLE 1 Summary of boundary condition recommendations

\begin{tabular}{clll} 
& $\begin{array}{l}\text { BC } \\
\text { Assumption }\end{array}$ & Accuracy & $\begin{array}{l}\text { Computational } \\
\text { Expense }\end{array}$ \\
$\begin{array}{c}\text { Solid } \\
\text { temperature } \\
\text { model }\end{array}$ & $\begin{array}{c}\text { FE solid } \\
\text { temperature } \\
\text { CFD solid } \\
\text { temperature }\end{array}$ & $\mathrm{X}$ & $\mathrm{X}$ \\
$\begin{array}{c}\text { Heat transfer } \\
\text { coefficient }\end{array}$ & $\begin{array}{l}\mathrm{WW} / \mathrm{m}^{2} \mathrm{~K} \\
\mathrm{CFD}\end{array}$ & $\mathrm{X}$ \\
Emissivity & 0.7 & $\mathrm{X}$ & $\mathrm{X}$ \\
& 0.9 & & $\mathrm{X}$ \\
\hline
\end{tabular}

\section{0 | CONCLUSIONS}

This study considered the effect of varying solid heat transfer models, heat transfer coefficients, and surface emissivities on the mechanical and thermal response of structural members subjected to a localized fire modeled using a coupled CFD-FE model. The results are summarized in Table 1. The " $X$ " in the tables denotes either the most accurate or computationally efficient choice for each category (solid temperature model, emissivity, etc). The recommendations made by this study valued accuracy over computational expense. The main conclusions are as follows:

- The FEM prediction of surface temperature should be used when determining boundary conditions. 
- The heat transfer coefficient for a localized fire scenario cannot be accurately represented by a constant value. The heat transfer coefficient can vary significantly over the structural member, and therefore, when possible, a spatially and temporally varying heat transfer coefficient determined by the CFD code should be used.

- A surface emissivity value of 0.9 should be used for localized fire scenarios of steel structures modeled using a coupled CFD-FE approach.

The recommendations presented by this study are limited to oneway coupled CFD-FE analyses of localized fires on an isolated steel structural member. The recommendations from this study are only based on the two cases shown and should therefore be extrapolated with care. Possible future work includes investigating if this approach is accurate and computationally efficient for other structural fire problems, such as larger structural systems, concrete and composite systems, combustible assemblies, or a hybrid localized-traveling fire.

\section{DISCLAIMER}

Certain commercial entities, products, or materials are identified in this document to describe a procedure or concept adequately. Such identification is not intended to imply recommendation, endorsement, or implication that the entities, product, or materials are necessarily the best available for the purpose.

\section{ACKNOWLEDGEMENTS}

This work was supported by the Gerstacker Fellowship and the Regents Fellowship at the University of Michigan. This research was also supported in part through computational resources and services provided by the University of Michigan's Advanced Research Computing (ARC) Flux HPC cluster.

\section{ORCID}

Alyssa DeSimone (D) https://orcid.org/0000-0002-8716-2285

\section{REFERENCES}

1. Zhang C, Li GQ, Usmani A. Simulating the behavior of restrained steel beams to flame impingement from localized-fires. J Constr Steel Res. 2013;83:156-165. https://doi.org/10.1016/j.jcsr.2013.02.001

2. Dwaikat MMS, Kodur VKR, Quiel SE, Garlock MEM. Experimental behavior of steel beam-columns subjected to fire-induced thermal gradients. J Constr Steel Res. 2011;67(1):30-38. https://doi.org/10.1016/j. jcsr.2010.07.007

3. Zhang C, Choe L, Seif M, Zhang Z. Behavior of axially loaded steel short columns subjected to a localized fire. J Constr Steel Res. 2015;111:103-111. https://doi.org/10.1016/j.jcsr.2014.11.012
4. Wickström U. Temperature Calculation in Fire Safety Engineering; Springer, Cham, Switzerland 2016. https://doi.org/10.1007/978-3319-30172-3.

5. EN 1991-1-2. Eurocode 1: Actions on structures-part 1-5: general actions-actions on structures exposed to fire. Eurocode 1. 2002;2 (2002):61

6. Tondini N, Morbioli A, Vassart O, Lechêne S, Franssen JM. An integrated modelling strategy between a CFD and an FE software: methodology and application to compartment fres. J Struct Fire Eng. 2016;7(3):217-233. https://doi.org/10.1108/JSFE-09-2016-015

7. Zhang C, Li GQ, Wang R. Using adiabatic surface temperature for thermal calculation of steel members exposed to localized fires. Int J Steel Struct. 2013;13(3):547-556. https://doi.org/10.1007/s13296-0133013-2

8. Silva JCG, Landesmann A, Ribeiro FLB. Fire-thermomechanical interface model for performance-based analysis of structures exposed to fire. Fire Saf J. 2016;83:66-78. https://doi.org/10.1016/j.firesaf.2016.04.007

9. Zhang C, Silva JG, Weinschenk C, Kamikawa D, Hasemi Y. Simulation methodology for coupled fire-structure analysis: modeling localized fire tests on a steel column. Fire Technol. 2016;52(1):239-262. https://doi. org/10.1007/s10694-015-0495-9

10. LaMalva KJ. Structural Fire Engineering. American Society of Civil Engineers, Reston, VA: 2018.

11. Kamikawa D, Hasemi Y, Yamada K, Nakamura M. Mechanical responses of a steel column exposed to a localized fire. In the proceedings of the fourth international workshop on structures in fire. 2006: 225-234.

12. Higginson S, Morris G. Modelling heat transfer to a steel-beam. Master's in engineering Thesis, University of Edinburgh; 2012.

13. Beata PA, Jeffers AE. Spatial homogenization algorithm for bridging disparities in scale between the fire and solid domains. Fire Saf J. 2015;76:19-30. https://doi.org/10.1016/j.firesaf.2015.05.008

14. Yu X, Jeffers AE. A comparison of subcycling algorithms for bridging disparities in temporal scale between the fire and solid domains. Fire Saf J. 2013;59:55-61. https://doi.org/10.1016/j.firesaf.2013.03.011

15. Mcgrattan K, Mcdermott R. Sixth Edition Fire Dynamics Simulator User's Guide; 2016. https://doi.org/10.6028/NIST.SP.1019.

16. Wickström U, Hunt S, Lattimer B, Barnett J, Beyler C. Technical comment-ten fundamental principles on defining and expressing thermal exposure as boundary conditions in fire safety engineering. Fire Mater. 2018:42:985-988.

17. Incropera F, Dewitt D. Fundamentals of Heat and Mass Transfer. Hoboken, NJ: John Wiley; 2011.

How to cite this article: DeSimone A, Jeffers AE. Best practices for modeling structural boundary conditions due to a localized fire. Fire and Materials. 2020;44:409-422. https:// doi.org/10.1002/fam.2774 